03,08

\title{
Радиационная стойкость кремниевых солнечных элементов, легированных никелем
}

\author{
(ㄷ К.А. Исмайлов ${ }^{1}$, З.Т. Кенжаев ${ }^{1,2}$, С.В. Ковешников ${ }^{2}$, Е.Ж. Косбергенов ${ }^{1, \uparrow}$, Б.К. Исмайлов ${ }^{2}$ \\ ${ }^{1}$ Каракалпакский государственный университет, \\ Нукус, Узбекистан \\ 2 Ташкентский государственный технический университет, \\ Ташкент, Узбекистан \\ ฯ E-mail: ernazar.kosbergenov@gmail.com
}

Поступила в Редакцию 7 декабря 2021 г.

В окончательной редакции 7 декабря 2021 г.

Принята к публикации 15 декабря 2021 г.

Исследовано влияние легирования никелем на радиационную стойкость кремниевых солнечных элементов в интервале доз $\gamma$-облучении $10^{5}-10^{8} \mathrm{rad}$. Показано, что диффузионное легирование кремния примесными атомами никеля увеличивает радиационную стойкость параметров кремниевых солнечных элементов. Предполагается, что причиной повышения радиационной стойкости таких солнечных элементов является существование кластеров примесных атомов никеля, которые служат стоками для радиационных дефектов.

Ключевые слова: кремний, $\gamma$-облучения, никель, кластер, солнечный элемент.

DOI: $10.21883 /$ FTT.2022.05.52330.253

\section{1. Введение}

Высокая чувствительность монокристаллического кремния и кремниевых приборов к воздействию радиации привела к тому, что в последнее время проблемы влияния радиации на физические свойства материалов, характеристики, надежность и стабильность работы приборов космической полупроводниковой электроники стали весьма актуальными. В связи с этим, возникла необходимость прогнозирования поведения полупроводниковых приборов в радиационных полях, а также разработки и создания электронных приборов с повышенной радиационной стойкостью.

Эффективность радиационного воздействия в большой мере зависит от степени совершенства исходных материалов, характера их легирования, структуры $p-n$ переходов $[1,2]$. Следует отметить, что наличие примесных атомов в объеме кристалла приводит не только к образованию новых дефектов, но также существенно влияет на скорости генерации различных радиационных дефектов (РД) [3-7]. При этом роль примесных атомов при облучении образцов в основном определяется их коэффициентом диффузии, растворимостью и состоянием (в том числе зарядовым) примесных атомов в решетке кремния.

В работах [8-11] показано, что в образцах кремния, легированных никелем, наблюдается формирование кластеров примесных атомов никеля в решетке кремния. Управляя условиями (температура, время и скорость охлаждения) диффузии никеля можно изменить радиационную стабильность кремния [12-14]. С увеличением концентрации вводимых примесных атомов никеля улучшается радиационная стабильность $\mathrm{Si}\langle\mathrm{Ni}\rangle$ [13].
В работах [14-19] показано, что легирование примесными атомами никеля кремниевого СЭ приводит к улучшению его эффективности. Однако радиационная стойкость таких СЭ не изучена.

Целю настоящей работы являлось исследование радиационной стойкости кремниевых солнечных элементов (СЭ), легированных никелем методом диффузии.

\section{2. Экспериментальная часть}

Для исследования влияния $\gamma$-облучения на параметры СЭ в качестве исходного материала использовались кремниевые пластины $p$-типа толщиной $d=380 \mu \mathrm{m} \mathrm{c}$ удельным сопротивлением $\rho=0.5 \Omega \cdot$ см (КДБ-0.5).

Затем на основе этих образцов, получены СЭ без примесных атомов никеля (группа I) и СЭ, легированные никелем до формирования $p-n$-перехода (группа II).

Для получения СЭ II группы на поверхность кремниевых пластин в вакууме напылялся слой чистого никеля толщиной $1 \mathrm{mkm}$, и проводилась диффузия никеля при температурах $T=800,1000$ и $1200^{\circ} \mathrm{C}$ в течение $t=30$, $10,3 \mathrm{~min}$. Затем создавался $p-n$ переход диффузией фосфора в „никелевую“ сторону пластины при $T=1000^{\circ} \mathrm{C}$ в течение $t=30 \mathrm{~min}$. После диффузии проводился дополнительный термоотжиг при оптимальной температуpe [16] $T=750-800^{\circ} \mathrm{C}$ в течение $t=30 \mathrm{~min}$.

СЭ группы I изготавливались по той же технологии, исключая напыление и диффузию никеля.

После каждого технологического этапа проводилась очистка поверхности и химическая обработка (в $10 \% \mathrm{HCl}$, затем в $10 \% \mathrm{HF}$ ), чтобы удалить остатки никеля и оксид кремния с поверхности СЭ. Просветляющее покрытие на поверхности элементов отсутствовало. 
Средние значения параметров СЭ

\begin{tabular}{c|c|c|c|c}
\hline \multicolumn{1}{|c|}{ Группа } & \multicolumn{1}{|c|}{ I } & II (1200) & II (1000) & II (800) \\
\hline$J_{\mathrm{sc}}, \mathrm{mA} / \mathrm{cm}^{2}$ & 32 & 33 & 36 & 38.5 \\
$V_{\mathrm{oc}}, \mathrm{mV}$ & 590 & 590 & 590 & 605
\end{tabular}

Пр и м е ч а н и е. Группа II (1200), II (1000), II (800) - СЭ, легированные никелем при температуре $T=1200,1000,800^{\circ} \mathrm{C}$ соответственно.

После получения омических контактов для всех образцов при одинаковых условиях были измерены ВАХ СЭ и определены основные параметры - напряжение холостого хода $V_{\text {ос }}$, плотность тока короткого замыкания $J_{\text {sc }}$ (таблица).

Для определения критериев устойчивости параметров СЭ к радиационному воздействию были проведены эксперименты по их облучению в интервале доз $\Phi=10^{5}-10^{8} \mathrm{rad}$. Облучение СЭ $\gamma$-квантами проводилось поэтапно: $\Phi=10^{5}, 10^{6}, 10^{7}, 5 \cdot 10^{7}, 10^{8} \mathrm{rad}$ при помощи изотопа $\mathrm{Co}^{60}(\sim 1.17 \mathrm{MeV})$ при температуре $T_{\mathrm{rad}}=300 \mathrm{~K}$. После каждого этапа облучения $\gamma$-квантами измерялись основные параметры СЭ. Получены $V_{\text {ос.0 и }}$

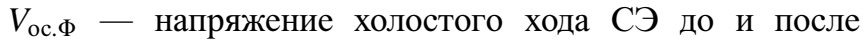
$\gamma$-облучения и $J_{\mathrm{sc} .0}$ и $J_{\mathrm{sc} . \Phi}-$ плотность тока короткого замыкания СЭ до и после $\gamma$-облучения.

Результаты экспериментов показали, что параметры кремниевых СЭ снижаются с увеличением дозы $\gamma$-облучения. Воздействие $\gamma$-излучения на кремниевые СЭ начинает ощущаться, когда доза облучения превышает $\Phi=10^{6} \mathrm{rad}$. Установлено, что более чувствительным к воздействию $\gamma$-облучения оказался ток короткого замыкания.

На рис. 1 представлены зависимость $J_{\text {sc.Ф }} / J_{\text {sc.0 }}-$ отношение плотностей тока короткого замыкания от дозы $\gamma$-облучения. При дозе $\gamma$-облучения $\Phi=10^{8} \mathrm{rad}$ плотность тока короткого замыкания СЭ группы I уменьшилась на 41.3\%. В то же время, плотность тока короткого замыкания СЭ группы II (800) уменьшилась на $26.9 \%$, а в СЭ группах II (1000) и II (1200) упала на $31 \%$ и $28.3 \%$ соответственно.

На рис. 2 представлены зависимости $V_{\text {ос } / \Phi} / V_{\text {ос. } 0}-$ отношение напряжений холостого хода от дозы $\gamma$-облучения. При дозе $\gamma$-облучения $\Phi=10^{8} \mathrm{rad}$ напряжение холостого хода СЭ группы II (800), II (1000) и II (1200) уменьшается на $10.5 \%, 12.9 \%$ и $7.96 \%$, соответственно. Напряжение холостого хода СЭ группы I ухудшалось на $18.2 \%$ (рис. 2 ).

\section{3. Обсуждение результатов}

Известно, что при облучении $\gamma$-квантами в кремнии создаются точечные радиационные дефекты - смешенные из узлов атомы кремния и свободные вакансии, обладающие достаточно большим коэффициентом диффузии и малыми энергиями миграции [2,20]. Благодаря этому они мигрируют по объему кристалла кремния и

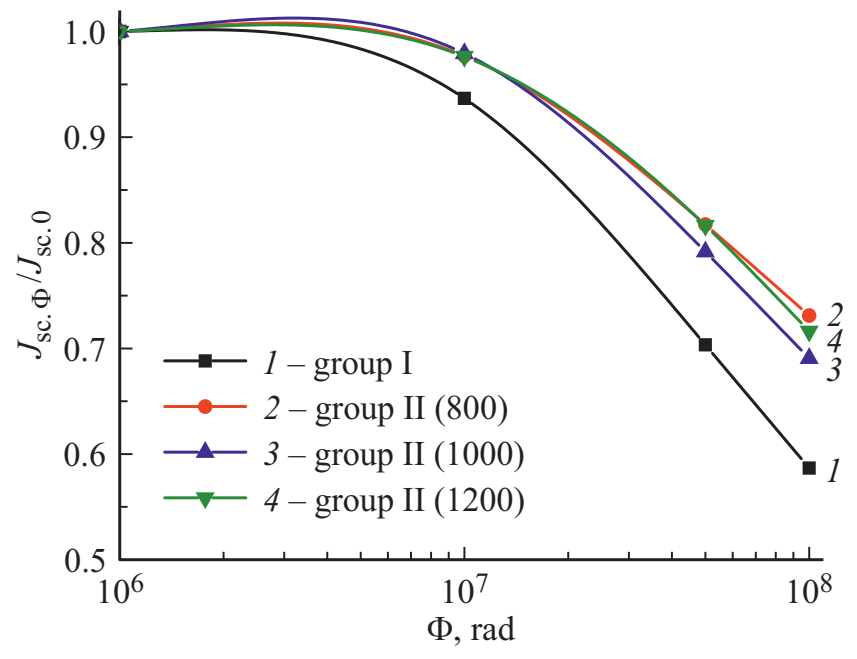

Рис. 1. Относительное изменение плотности тока короткого замыкания СЭ от дозы $\gamma$-облучения.

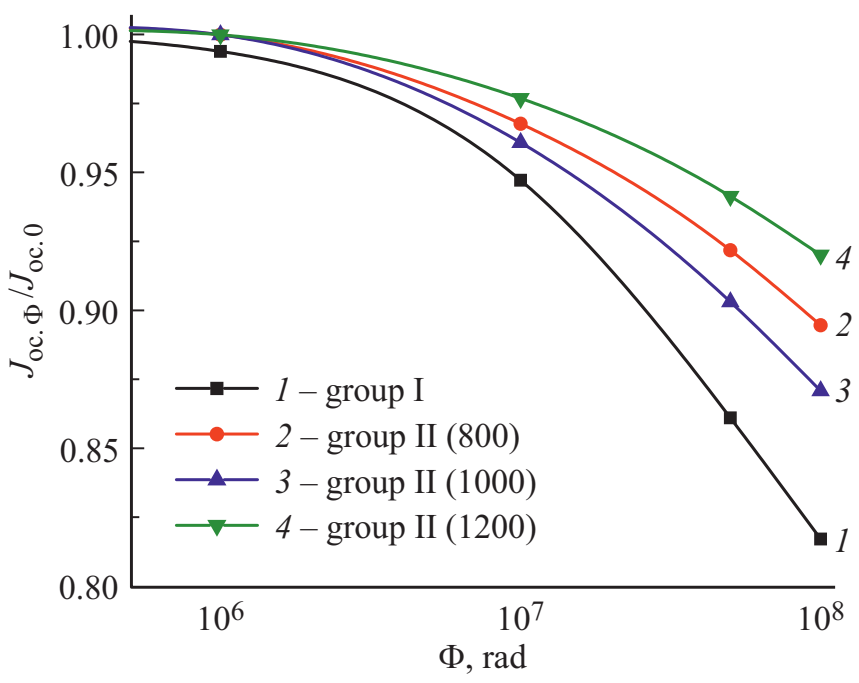

Рис. 2. Относительное изменение напряжения холостого хода СЭ от дозы $\gamma$-облучения.

взаимодействуют между собой и с атомами легирующих и фоновых примесей в кремнии.

Результаты исследований влияния облучения на свойства образцов групп II (рис. 1 и 2) показывают, что облучение приводит к различию в электрических параметрах СЭ по сравнению с образцами групп I. При облучении $\gamma$-квантами образцов из группы II их параметры меняются заметно меньше, чем параметры образцов группы I. Это свидетельствует о том, что примеси атомов никеля влияют на образование радиационных дефектов. В то же время радиационная стабильность параметров СЭ группы II заметно улучшается с увеличением температуры диффузии никеля. Если учесть, что с увеличением температуры диффузии, растворимость никеля увеличивается $[21,22]$, то можно утверждать, что 
радиационная стабильность СЭ группы II зависит от концентрации атомов никеля, вводимых при диффузии.

Примеси атомов никеля в основном находятся в междоузлиях и обладают достаточно большим коэффициентом диффузии [21,22], а также активно взаимодействуют с атомами кислорода [23,24]. Радиационные дефекты, возникающие в процессе облучения, имеют большую вероятность встречи с атомами никеля. Основными центрами захвата и аннигиляции вакансий и междоузельных атомов кремния, видимо, служат междоузельные электронейтральные атомы никеля, которые могут находятся в виде кластеров [8-11].

\section{4. Заключение}

Экспериментально показано, что легирование никелем улучшает радиационную стойкость кремневых СЭ и радиационная стойкость СЭ увеличивается с увеличением концентрации атомов никеля. Мы предполагаем, что в СЭ, легированных никелем, при облучении $\gamma$-квантами, первоначальные радиационные дефекты нейтрализуются кластерами атомов никеля.

Из полученных результатов можно сделать следующие выводы:

- легирование атомами никеля улучшает радиационную стойкость кремниевых СЭ по току короткого замыкания до $15 \%$ и по напряжению холостого хода до $10 \%$ по сравнению с контролем $\left(\Phi=10^{8} \mathrm{rad}\right)$.

- положительный эффект атомов никеля зависит от температуры диффузии никеля, достигая максимума при $1200^{\circ} \mathrm{C}$.

\section{Благодарности}

Авторы выражают глубокую и искреннюю благодарность профессору М.К. Бахадырханову за ценные советы, данные при выполнении работы и обсуждении полученных результатов.

\section{Конфликт интересов}

Авторы заявляют об отсутствии конфликта интересов.

\section{Список литературы}

[1] Ф.П. Коршунов, Г.В. Гатальскин, Г.М. Иванов. Радиационные эффекты в полупроводниковых приборах. Наука и техника. М. (1978). 232 с.

[2] Sh. Makhkamov, R.A. Muminov, M. Karimov, N.A. Tursunov, A.R. Sattiev, M.N. Erdonov, Kh.M. Kholmedov. Appl. Sol. Energy 49, 2, 62 (2013).

[3] Sh. Makhkamov, R.A. Muminov, M. Karimov, K.P. Abdurakhmanov, N.A. Tursunov, A.R. Sattiev, M.N. Erdonov, Kh.M. Kholmedov. Appl. Sol. Energy 49, 4, 185 (2013).

[4] Sh. Makhkamov, M. Karimov, Z.M. Khakimov, N.Dj. Odilov, Sh.A. Makhmudov, A.O. Kurbanov, K.A. Begmatov. Rad. Effects Defects Solids 160, 8, 349 (2005).
[5] А.В. Заставной, В.М. Король. ФТП 23, 2, 369 (1989).

[6] Ф.М. Талипов. ФТП 31, 5, 515 (1997).

[7] Ю.А. Карпов, В.В. Петров, В.С. Просолович, В.Д. Ткачев. ФТП 17, 8, 1530 (1983).

[8] M.K. Bakhadyrkhanov, Kh.M. Iliev, K.S. Ayupov, B.A. Abdurakhmonov, P.Yu. Krivenko, R.L. Kholmukhamedov. Inorg. Mater. 47, 9, 962 (2011).

[9] M.K. Bakhadyrkhanov, K.A. Ismailov, B.K. Ismaylov, Z.M. Saparniyazova. SPQEO 21, 4, 392 (2018).

[10] M.K. Bakhadyrkhanov, B.K. Ismaylov, S.A. Tachilin, K.A. Ismailov, N.F. Zikrillaev. SPQEO 23, 4, 361 (2020).

[11] B.A. Abdurakhmanov, M.K. Bakhadirkhanov, K.S. Ayupov, H.M. Iliyev, E.B. Saitov, A. Mavlyanov, H.U. Kamalov. Nanosci. Nanotechnol. 4, 2, 23 (2014).

[12] K.M. Iliev, Z.M. Saparniyazova, K.A. Ismailov, O.E. Sattarov, S. Nigmonkhadzhaev. Surf. Eng. Appl. Electrochem. 47, 5, 385 (2011). DOI: 10.3103/s1068375511050103

[13] S.S. Nasriddinov. J. nano-and Electron. Phys. 7, 3, 5 (2015).

[14] С.3. Зайнабидинов, А.О. Курбанов. Узбек. физ. журн. 20, 2 , 105 (2018).

[15] М.К. Бахадырханов, С.Б. Исамов, 3.Т. Кенжаев, С.В. Ковешников. Письма в ЖТФ 45, 19, 3 (2019).

[16] М.К. Бахадырханов, 3.Т. Кенжаев. ЖТФ 91, 6, 981 (2021).

[17] М.К. Бахадырханов, 3.Т. Кенжаев, С.В. Ковешников, К.С. Аюпов, Е.Ж. Косбергенов. ФТП 56, 1, 128 (2022).

[18] М.К. Бахадырханов, 3.Т. Кенжаев, К.А. Исмайлов, С.В. Ковешников. Гелиотехника 56, 4, 322 (2020).

[19] М.К. Бахадырханов, 3.Т. Кенжаев, Х.С. Турекеев, Б.О. Исаков, А.А. Усмонов. ЖТФ 91, 11, 1685 (2021).

[20] V.V. Lukjanitsa. Semiconductors 37, 4, 404 (2003). DOI: https://doi.org/10.1134/1.1568459

[21] A.A. Istratov, P. Zhang, R.J. McDonald, A.R. Smith, M. Seacrist, J. Moreland, J. Shen, R. Wahlich, E.R. Weber. J. Appl. Phys. 97, 023505 (2005). DOI: 10.1063/1.1836852

[22] J. Lindroos, D.P. Fenning, D.J. Backlund, E. Verlage, A. Gorgulla, S.K. Estreicher, H. Savin, T. Buonassisi. J. Appl. Phys. 113, 204906 (2013). DOI: 10.1063/1.4807799

[23] Б.К. Исмайлов, А.Б. Камалов, Д.Ж. Асанов. Приборы 252, 6, 25 (2021).

[24] М.К. Бахадирханов, Б.К. Исмайлов. Приборы 240, 6, 44 (2020).

Редактор К.В. Емцев 